\title{
Coronavirus disease 2019 and flight safety
}

\author{
Sevgi ÖZcan (1)
}

Department of Cardiology, Bağclar Training and Research Hospital; İstanbul-Turkey

\section{ABSTRACT}

Air traffic has been a main vector for the global spread of COVID-19. The risk of in-flight transmission can vary widely, depending on different parameters. Therefore, implementation of measures for air travel safety is very important.

Keywords: COVID-19, flight, transmission

\section{Introduction}

A novel coronavirus named severe acute respiratory syndrome coronavirus 2 (SARS-CoV-2) emerged in China in late December 2019 and caused a respiratory disease, named coronavirus disease 2019 (COVID-19). The first appearance of COVID19 in Wuhan and other cities in China was triggered by the lack of respiratory and contact precautions and people attending meetings. It has been reported that even short-term contact with patients with COVID-19 can lead to infection, and asymptomatic individuals too can spread the SARS-CoV-2 infection (1). COVID-19 can be transmitted through respiratory droplets, contact with infected persons, and possibly fecal-oral transmission (2). COVID-19 often occurs in family or social groups, and public transport can be a major factor for transmission.

The spread of the disease can be controlled with the implementation of control measures. COVID-19 spread rapidly around the world, largely owing to the fact that people infected with SARS-CoV-2 traveled to other countries by airplane. Therefore, taking effective precautions during public transportation is one of the most important control measures to prevent COVID-19 spread. A large number of people traveling internationally represents an important element for the transmission of COVID-19 $(3,4)$. As COVID-19 transmissions spread globally, almost all governments announced and enforced both domestic and international travel restrictions. Although some countries have completely shut down border crossings and restricted flights in affected areas, others have implemented fever measurements and 2-week-long selfquarantine for travelers to contain further spread of COVID-19 (5).
These restrictions, of course, greatly affected the airline industry and tourism sector and had a great impact on national economies (6). With travel restrictions, the global flight network gradually became sparser, which generally prevented travelers using direct flights to their destinations. Decisions about whether and how to restrict air traffic from severely affected countries remain difficult as the extent of COVID-19 varies widely between different countries, from very high numbers to no or only a few cases.

\section{Risk of in-flight COVID-19 transmission and the necessary precautions to minimize transmission risk}

Air traffic has been a main vector for the global spread of COVID-19. The risk of in-flight transmission can vary widely, depending on whether people wear masks; on the physical proximity to the index patient(s), the stage of illness, and the number of index patient(s); the type of air-ventilation system; size of the aircraft cabin; and the duration of the flight $(7,8)$. A low rate of in-flight transmission of SARS-CoV has been documented in most research reports, showing that it is only moderately transmitted in aircraft cabins $(9,10)$, although SARS-CoV-2 may have a higher risk of inflight transmission than SARS-CoV. Close contact was probably the most important in-flight mode of transmission for influenza (almost $70 \%$ ), although fomite mostly contributed to close contact and airborne transmission of SARS-CoV (11). There are no exact data on routes of transmission of in-flight COVID-19. Similar to influenza, host-related risk factors such as advanced age and immunodeficiency, together with environmental factors such as public and

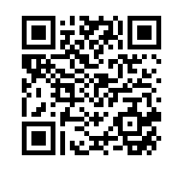

Address for Correspondence: Dr. Sevgi Özcan, Department of Cardiology,

Bağcılar Training and Research Hospital; İstanbul-Turkey

Phone: +90 5332332033 E-mail: sevgibozcan@gmail.com 
social gatherings, may contribute to in-flight transmission of COVID-19. Factors that increase the risk of in-flight transmission of respiratory pathogens include the possibility of airborne spread; transmissibility during asymptomatic, mild, or non-symptomatic periods; as well as a long incubation period. Wilder-Smith et al. (12) reported the first case of in-flight transmission of SARS-CoV from Singapore. They suggested that it was unlikely to have a massive transmission of SARS-CoV on airplanes, especially when respiratory and contact precautions are in place.

There are some measures that can reduce the risk of in-flight transmission of SARS-CoV-2: minimizing the number of flights to and from areas severely affected by the COVID-19 outbreak, strict pre-flight screening to find symptomatic people, and the proper use of masks by passengers and crew during flight (13). It is strongly suggested to implement mask use and strict hand hygiene for passengers, flight attendants, and pilots. These measures must be taken before boarding, during the flight, and after disembarking during the COVID-19 pandemic. Airline companies should supply hygiene kits for all the passengers.

In airplanes, the coronavirus is less likely to spread through air than by touch, as aircraft air conditioning systems are capable of filtering particles as small as viruses (high-efficiency particulate air filtration). Approximately $50 \%$ of the air is recirculated, and the rates of air exchange reported by the manufacturers of these types of aircraft range from 6 to 20 times per hour. However, the way air in airplane cabins is distributed through the air conditioning system can cause the virus to be transmitted to other passengers sitting in the same row as an infected passenger or even to those sitting in a neighboring row. Air blast nozzles located just above the seats in airplanes can affect the risk of infection for passengers. It is useful to keep these nozzles closed. The aircraft ventilation system should be operated before passengers are boarded and should never be turned off.

The World Health Organization's working definition of a contact on a flight is any passenger seated in the same row of seats or within 2 seats in front of or behind the index patient or any flight attendant (14). Presymptomatic and symptomatic patients are all reported to be equally effective in the spread of SARS-CoV-2 (1, 15). In the presence of a passenger developing fever and/or respiratory symptoms during a flight, the passenger is to put on a mask and, if possible, be seated in the rightmost rear seat of the aircraft, and a single cabin crew member takes care of that passenger. The cabin personnel in contact with the suspected patient should be on leave at home until the test result of the suspected patient is obtained. If the test result of the suspected patient is positive, flight permit is not given to the cabin crew for 7 days after contact. On the seventh day, the cabin personnel are tested for SARSCoV-2. If the pilots were not in the passenger cabin, they continue their work as they are not at risk.

As the global epidemiology of COVID-19 evolves, travelerrelated issues will require constant updating. According to the available data, it is important that the crew and passengers wear masks, and their temperature is screened in and out of the aircraft. Prompt detection and isolation of patients with symptomatic COVID-19 and implementation of appropriate measures in flight are imperative for prevention of transmission. Continuous flight services likely played an important role in the spread of COVID-19.

\section{Conclusion}

Air travel is a major cause for the international spread of COVID-19. International air traffic is breaking down with increasing COVID-19 cases in many countries. Air travel restrictions have a great social and economic burden; therefore, implementing preventive strategies for safe air travel is crucial to continue air link between cities and countries.

Conflict of interest: None declared.

\section{References}

1. Huang R, Xia J, Chen Y, Shan C, Wu C. A family cluster of SARSCoV-2 infection involving 11 patients in Nanjing, China. Lancet Infect Dis 2020; 20: 534-5. [Crossref]

2. Guan WJ, Ni ZY, Hu Y, Liang WH, Ou CQ, He JX, et al.; China Medical Treatment Expert Group for Covid-19. Clinical Characteristics of Coronavirus Disease 2019 in China. N Engl $\mathrm{J}$ Med 2020; 382: 1708-20. [Crossref]

3. Rodríguez-Morales AJ, MacGregor K, Kanagarajah S, Patel D, Schlagenhauf P. Going global - Travel and the 2019 novel coronavirus. Travel Med Infect Dis 2020; 33: 101578. [Crossref]

4. Wilson ME, Chen LH. Travellers give wings to novel coronavirus (2019-nCoV). J Travel Med 2020; 27: taaa015. [Crossref]

5. Lau H, Khosrawipour V, Kocbach P, Mikolajczyk A, Schubert J, Bania $\mathrm{J}$, et al. The positive impact of lockdown in Wuhan on containing the COVID-19 outbreak in China. J Travel Med 2020; 27: taaa037. [Crossref]

6. Suzumura T, Kanezashi H, Dholakia M, Ishii E, Napagao S, Raquel PérezArnal, etal. The Impact of COVID-19 on Flight Networks. IEEE International Conference on Big Data (Big Data) 2020; 2443-52. [Crossref]

7. Kenyon TA, Valway SE, Ihle WW, Onorato IM, Castro KG. Transmission of multidrug-resistant Mycobacterium tuberculosis during a long airplane flight. N Engl J Med 1996; 334: 933-8. [Crossref]

8. Moser MR, Bender TR, Margolis HS, Noble GR, Kendal AP, Ritter DG. An outbreak of influenza aboard a commercial airliner. Am J Epidemiol 1979; 110: 1-6. [Crossref]

9. Breugelmans J, Zucs P, Porten K, Broll S, Niedrig M, Ammon A, et al. SARS transmission and commercial aircraft. Emerging Infect Dis 2004; 10: 1502-3. [Crossref]

10. Wilder-Smith A, Paton N, Goh K. Low risk of transmission of severe acute respiratory syndrome on airplanes: the Singapore experience. Trop Med Int Health 2003; 8: 1035-7. [Crossref]

11. Lei H, Li Y, Xiao S, Lin CH, Norris SL, Wei D, et al. Routes of transmission of influenza A H1N1, SARS CoV, and norovirus in air cabin: comparative analyses. Indoor Air 2018; 28: 394-403. [Crossref]

12. Wilder-Smith A, Leong H, Villacian J. In-flight transmission of Severe Acute Respiratory Syndrome (SARS): a case report. J Travel Med 2003; 10: 299-300. [Crossref]

13. Olsen SJ, Chang HL, Cheung TY, Tang AF, Fisk TL, Ooi SP, et al. Transmission of the severe acute respiratory syndrome on aircraft. N Engl J Med 2003; 349: 2416-22. [Crossref]

14. WHO recommended measures for persons undertaking international travel from areas affected by severe acute respiratory syndrome (SARS). Wkly Epidemiol Rec 2003; 78: 97-9.

15. Bai Y, Yao L, Wei T, Tian F, Jin DY, Chen L, et al. Presumed Asymptomatic Carrier Transmission of COVID-19. JAMA 2020; 323: 1406-7. [Crossref] 